\title{
The Effect of Graduated Response Anti-Piracy Laws on Music Sales: Evidence from an Event Study in France
}

\author{
Brett Danaher \\ Wellesley College, Department of Economics \\ Michael D. Smith ${ }^{+}$ \\ Carnegie Mellon University, Heinz College \\ Rahul Telang ${ }^{\dagger}$ \\ Carnegie Mellon University, Heinz College \\ Siwen Chen \\ Wellesley College, Department of Economics
}

This Version: January 2012

Acknowledgements: The authors thank four major record labels for generously providing data to support this research. Smith and Telang acknowledge generous support from Carnegie Mellon's iLab.

$¥ \quad$ Department of Economics, Wellesley College, Wellesley, MA, 02481

+ School of Information Systems and Management, Heinz College, Carnegie Mellon University, Pittsburgh, PA, 15213. 


\title{
The Effect of Graduated Response Anti-Piracy Laws on Music Sales: Evidence from an Event Study in France
}

\begin{abstract}
The digital piracy is a significant problem for the creative industries. Still, while there have been many academic studies showing that piracy hurts sales, there have been far fewer studies analyzing the effectiveness of anti-piracy measures in reversing this effect. This study attempts to address this gap in the literature by analyzing how the HADOPI "three strikes" law in France affected digital music sales on the iTunes music store.

To do this, we obtained a panel of iTunes sales data for the four major music labels (Universal Music, Warner Music, EMI Music and Sony Music) across a broad set of countries. We then applied a difference-in-difference approach, using sales trends in a control group of European countries to simulate the counterfactual of what music sales in France would have been if HADOPI had not been passed. Our results suggest that increased consumer awareness of HADOPI caused iTunes song and album sales to increase by $22.5 \%$ and $25 \%$ respectively relative to changes in the control group.

In terms of robustness, we find that these sales changes are similar for each of the four major music labels, suggesting that our results are not driven by one particular label. We also find that the observed sales increase is much larger in genres that, prior to HADOPI, experienced high piracy levels (e.g., Rap and Hip Hop) than for less pirated genres (e.g., Christian music, classical, and jazz). This tends to strengthen the causal interpretation of our results given that if HADOPI is causing pirates to become legitimate purchases, its effects should be stronger for heavily pirated music.
\end{abstract}

Keywords: Piracy, regulation, digital distribution, music industry, natural experiment. 


\section{Introduction:}

Since the rise of Napster, "piracy killed the radio star" could be the global slogan of the music industry. Global recorded music sales and licensing have plunged from nearly \$27 billion US dollars in 2000 to $\$ 15$ billion in $2010,{ }^{1}$ with some countries witnessing a coinciding decrease in investment in developing local talent (IFPI 2010). An increasingly popular topic in the economics and the information systems literatures has been how much of this sales decrease is due to displacement by Internet piracy. While estimates vary, the vast majority of studies find that piracy has caused a significant decrease in music sales (see for example, Liebowitz (2006), Rob and Waldfogel (2004), Zentner (2006), Hui and Png (2003), OECD (2009)). However, to date there have been far fewer academic studies analyzing whether anti-piracy measures can mitigate some of the sales loss from piracy — and none that we are aware of that are directly related to governmental intervention. Our goal in this paper is to provide such evidence, by evaluating the effectiveness of anti-piracy government intervention in France.

Since the rise of Napster in 2000, media companies have pleaded with governments worldwide to consider and implement newer, more creative anti-piracy laws and strategies to mitigate the impact of piracy on sales. In May of 2009 the French Parliament passed an anti-piracy law known as HADOPI, or the Creation and Internet Law. The purpose of this law is to "promote the distribution and protection of creative works on the Internet." The law empowers the HADOPI administrative authority to send warnings to identified infringers and transfer the case to the court in cases of repeat infringement. HADOPI acts on the basis of information submitted by rightholders and has the power to monitor online infringement and verify information with ISPs. When a rightsholder submits a notice of infringement, it is verified by HADOPI and matched against information held by the relevant ISP. Valid infringement triggers a notice of infringement sent by email from HADOPI to the account holder. When the same account is identified again as being used for infringement within a period of six months of the first

\footnotetext{
${ }^{1}$ Source: IFPI. This includes both digital and physical sales of recorded music.
} 
warning, a second warning is sent by HADOPI to the account holder, this time by registered mail. Where the account is identified for a third time within a period of one year, HADOPI may escalate the case by referring it to the criminal court, where a single judge is empowered to order a range of penalties, including account suspension for up to one month. ${ }^{2}$ This law has been controversial on several major fronts, including the cost of the law, suggestions that Internet access may be a human right, potential violations of the principle of net neutrality, and the possibility that the law could hold Internet users responsible for copyright violations even if their computers have been hijacked.

The purpose of this study is not to debate the broader social and policy merits of this law. Instead, our purpose is to analyze whether this law had an impact on consumer behavior. ${ }^{3}$ This question is important for two reasons. First, music industry profits are clearly important to individuals working in that industry. Second, a broader social concern is that if the media industries are less able to recoup profits on their investments in creative works they will likely decrease their investment in bringing new music, television, and films to society, thus reducing overall social welfare.

In this regard, we evaluate the effectiveness of HADOPI using a panel of iTunes sales data for the four major music labels (Universal Music, Warner Music, EMI Music and Sony Music) across a broad set of countries. We employ a difference-in-difference approach, using sales trends in selected European countries to simulate the counterfactual of what music sales in France would have been if HADOPI had not been passed. Using Google Trends, we find that public awareness of HADOPI became widespread in Spring 2009, and our difference-in-difference model suggests that HADOPI awareness caused a 22.5\% increase in iTunes song unit sales in France (over and above any change in the control group), as well as a $25 \%$ increase in iTunes album unit sales (over and above the change in the control group). Closer

\footnotetext{
${ }^{2}$ See the HADOPI law itself in articles L 331-25 and L 336-2. Or an explanatory memorandum from the French government at http://www.culture.gouv.fr/culture/actualites/conferen/albanel/creainterenglish.pdf.

${ }^{3}$ We study digital sales for two reasons: first, the data are more readily quantifiable than physical sales are (unlike with digital sales, there are no comprehensive sources of physical sales data). Second, previous studies have shown that illegal Internet downloaders prefer digital sales channels over physical ones when purchasing legally. For example, see Danaher et al. (2010).
} 
examination reveals similar trends separately for each of the four major music labels, suggesting that our industry-wide results are not driven by one label's advertising campaign or marketing activity.

To test the validity of our results, we add another level of difference to the model. Previous research and new survey data reveal that music genres differ in their tendency to be pirated. One would expect that if the observed relative increase in French sales is caused by HADOPI, that high-piracy genres would experience a larger increase in sales than low-piracy genres do. Our results are consistent with this hypothesis: low piracy genres experienced only a $7 \%$ difference-in-difference sales increase in France after HADOPI, while high piracy genres experienced a 30\% difference-in-difference increase in sales. This suggests that the observed increase in French sales after HADOPI is indeed due to a reduction in Internet piracy.

\section{Background on Music Industry and HADOPI}

Looking at aggregate sales reports it's easy to see why the music industry might be concerned about the impact of piracy on sales. Forrester research and the Recording Industry Association of America (RIAA) have reported that music industry revenue in the United States dropped by $46 \%$ from $\$ 14.6$ billion in 1999 to $\$ 7.7$ billion in $2009 .{ }^{4}$ Worldwide sales have seen a similar drop of $44 \%$ from $\$ 27$ billion in 2000 to $\$ 15$ billion in 2010. Studies by the IFPI have found corresponding decreases in investment in local talent in some countries. However, the economic literature is only just beginning to address the question of whether diminished music industry returns due to piracy cause a decrease in the amount of creative works brought to the market. ${ }^{5}$ Nonetheless, academic studies on the effect of piracy suggest that online file sharing can explain anywhere from one fifth to all of the decrease in music industry revenues since

\footnotetext{
${ }^{4}$ http://www.riaa.com/faq.php

${ }^{5}$ See, for example, Oberholzer-Gee and Strumpf 2009 or Waldfogel 2011.
} 
$2000,{ }^{6}$ and it is important that we try to understand what sorts of policies or strategies can act to mitigate this negative impact.

In June 2008 the HADOPI Law was first presented to the French Senate by several politicians, and in October 2008 the Senate backed the law, meaning that it would next go before the French National Assembly (however, as we will show in more detail below, there was relatively low publicity around the law or national awareness of it during this time). In March 2009 the HADOPI law was presented to the National Assembly, where it was at first supported and then rejected in 2009. This debate gave rise to a number of media articles generating awareness and controversy. ${ }^{7}$ Importantly, this could have led to some confusion among the general populace over whether the law was yet effective or not. In May 2009 both the National Assembly and the Senate backed an amended version of the law, leading opposition Parliamentarians to send it to the French Constitutional Council for review. In June 2009 the Constitutional Council rejected the main part of the law (again potentially adding to confusion over whether the law was yet in effect), largely over the issue of judicial review for penalties imposed by the third strike — in this early version of the law, penalties could be applied to individuals on the third infringement without judicial review. This section was then amended to require judicial review, and the Constitutional Council accepted the amended law in October 2009, putting the law into effect. $^{8}$

From that point onward, filesharers in France could theoretically begin to receive notices of infringement. However, it was over a year before the HADOPI agency began sending out first notices, with the first wave of infringement notices going out in September 2010. Later, in Spring 2011, the HADOPI agency began the initial wave of second notices, and as of August 2011 no third notices had been sent out and no penalties had yet been applied. ${ }^{9}$

\footnotetext{
${ }^{6}$ See the music piracy studies cited in our literature review.

${ }^{7}$ For example, http://news.bbc.co.uk/2/hi/europe/7992262.stm

${ }^{8}$ For references regarding the political timeline of the HADOPI law, see law http://www.senat.fr/dossierlegislatif/pjl07-405.html and http://www.conseil-constitutionnel.fr/decision.42666.html.

${ }^{9}$ This timeline is outline in a short report titled 'Hadopi, cultural property and Internet usage: French Internet users' habits and points of view" available at http://www.hadopi.fr.
} 
It is also important to note that while the most publicized responsibility of the HADOPI agency under the law is to send out infringement notices, the agency also started an ongoing education campaign to inform citizens about the illegality of sharing copyrighted materials online, the dangers it may pose to content generation in the future, and the various legal channels in which media can be obtained. These campaigns are an ongoing part of HADOPI's responsibilities. Unfortunately (from a research perspective), these campaigns are ongoing and do not represent discrete events. Thus their effects cannot be separated from the effects of the graduated response/penalty portion of the law, and our study must be about the combined effect of any and all education campaigns combined with the warning and penalty system.

\section{Literature Review}

Our research is most closely related to the large literature analyzing how piracy has impacted media sales. This literature has used a variety of empirical methods from cross-country variation in piracy levels (e.g., Zentner 2005, Hui and Png 2003, Peitz and Waelbroeck 2004, and Danaher and Waldfogel 2011) to survey data (e.g., Rob and Waldfogel 2006, Rob and Waldfogel 2007) to exogeneous shocks in the availability of pirated or legitimate content (e.g., Oberholzer-Gee and Strumpf 2007, Smith and Telang 2009, Danaher et al. 2010). What this literature has in common is that nearly all of the academic studies find that media piracy has a significant negative impact on sales. The one exception to this rule, Oberholzer-Gee and Strumpf 2007, is also one of the earliest studies of piracy's impact, and has seen some concerns expressed about its findings in recent years (see Liebowitz 2008, Liebowitz 2011).

Our research is also closely related to a smaller literature on the impact of anti-piracy intervention on sales and the availability of pirated content. In this literature Bhattacharjee et al. (2008) analyze how the RIAA's legal threats against file sharers impacted sales. The authors treat the industry's legal intervention (and associated press coverage) in 2003 as a quasi-experiment, and find that the lawsuits had a statistically significant negative impact on the availability of pirated content, but that a substantial amount 
of illegal content was still available even after several highly publicized lawsuits against filesharers. Notably, however, this study did not address the impact of the lawsuits on sales.

In the context of the use of DRM, Desai et. al. (2009) and Sinha et al. (2010) argue that the use of DRM may increase piracy by making the content less usable for end-users. Similarly, Kemerer, Liu, and Smith (2011) argue that the use of DRM may make it more likely that a single dominant platform will emerge in digital media sales channels — potentially creating powerful downstream players, such as iTunes, for the industry to negotiate with. Finally, in the computer science literature Christin et al. (2005) have analyzed the effectiveness of file sharing "poisoning" strategies, finding that a few intentional decoys of pirated content can influence perceived availability of content in the networks.

Lastly, our study relates to a growing literature analyzing the impact of digital sales channels on sales in physical channels and on piracy. In this literature, Deleersnyder et al. (2002) show that the availability of digital news in England and the Netherlands has only a small impact of readership in physical channels. In the context of video distribution, Waldfogel (2009) uses survey data to find that YouTube viewing of television content has almost no impact of television viewership levels. Likewise, Danaher et al. 2010 find that iTunes distribution of television content has no statistical impact on sales of DVD box sets of that content, but a large negative impact on piracy levels. Finally, $\mathrm{Hu}$ and Smith (2011) find that the distribution of Kindle ebooks has a very low impact on sales of print books.

\section{Theory}

Our main theory of the impact of HADOPI is closely tied to the original intent of the law: HADOPI may cause consumers who otherwise would have pirated music to avoid piracy, and some of these consumers may instead purchase music through legitimate channels. There are, however, two important theoretical questions about the impact of the law that warrant discussion. First, when should we expect the impact of the HADOPI law? Will it occur primarily around national awareness of the law, or when the law actually 
goes into effect? Second, will HADOPI cause increased consumption of legal music and will this consumption occur in digital or physical channels?

With respect to the second question, as noted above, the literature seems to suggest that consumers are strongly tied to either the digital or physical channel such that if a consumer is forced to stop consuming digital piracy, the literature suggests that they are more likely to switch to other digital channels than they are to return to CD purchases (see, for example, Danaher et al. 2010, Hu and Smith 2011). Because of this, we focus on the impact of HADOPI on digital music sales, reflecting our belief that if HADOPI impacts individuals' ability to pirate online, they are more likely to turn to digital music channels than they are to go back to physical purchases of CDs.

However, since nearly all prior literature indicates that filesharing does indeed displace sales of physical music, it is a limitation of this paper that we are only able to examine iTunes sales data as it is very possible that HADOPI could affect physical sales as well. Unfortunately, physical retail sales data were not available to us at the time of this study and we suggest that our methodology could be applied to these data as well. Data from the Syndicat National de L'edition Phonographique (SNEP) indicate that 25\% of French music sales in the first 3 quarters of 2011 were digital ${ }^{10}$, with physical making up the remainder. Thus, our study asks the question of whether a law like HADOPI can stimulate sales of one form of media (music) in one channel (iTunes), and as such likely will not capture the total impact of the law.

With respect to the first question, there is no strong theoretical basis in the literature for whether HADOPI's impact will begin primarily when the public becomes aware of the law or with the actual dates of passage, legal notifications, and legal penalties. Many economic studies of policy changes focus on the date of passage of the new policy as the treatment date. However, because HADOPI went through a significant public and political debate before being passed, and because citizens may not have even been aware of the actual effective date of the law, we believe it possible that public awareness and salience of

\footnotetext{
${ }^{10} \mathrm{http}: / / \mathrm{www} \cdot$ disqueenfrance.com/fr/catalogpage. $\mathrm{xml}$ ?id=420906\&pg=1\&cat=251362
} 
the law could drive a change in behavior before it actually became effective. Lacking a strong theoretical basis, in our analysis below we test for both effects, finding a stronger impact around the peak awareness of HADOPI than from the specific passage of the law or the dates associated with first notifications of violations.

\section{Data}

For this study, we obtained a panel of total weekly iTunes sales units for a number of European countries including France. Our data extend from July 2008 to May 2011, and we observe separately both track unit sales and album unit sales. The data were obtained directly from the four major music labels EMI, Sony, Universal, and Warner - and aggregated to reflect total iTunes sales for the majors. According to the IFPI, the four majors reflect roughly $70 \%$ of music industry sales, with independent labels reflecting the other $30 \%$ not observed in our data. We chose the five European countries (other than France) with the highest iTunes sales levels as our control group for France, under the theory that overall market trends would have the most similar impact on countries with closer sales levels. ${ }^{11}$ Thus, in this study we observe weekly iTunes sales units for France, the UK, Italy, Spain, Germany, and Belgium. This yields 918 country-by-week observations of total iTunes sales units, broken down into albums and tracks.

We also have a separate dataset provided to us by just two of the four major labels. This dataset is similar to the dataset above except that for each country-week, we observe total iTunes song sales units for each genre of music. We use this dataset as a further test of our main effect, focusing on the following genres: Rap, Hip Hop, Rock, Pop, Classical, Christian, Folk, and Jazz. Our purpose in doing this was to keep

\footnotetext{
${ }^{11}$ However, any results reported in this paper are not sensitive to this selection of control group. Results remain roughly the same (and completely the same in sign and significance) when choosing a variety of other control groups).
} 
only genres which had a significant share of the market and for which we had reasonable priors regarding relative piracy levels for the genre. ${ }^{12}$

Table 1 shows the average sales levels (both track and album) across each of the countries as well as giving some indicators of the level of variance within each country.

Table 1: Descriptive Statistics

\begin{tabular}{lrrrrrrr}
\hline & \multicolumn{2}{c}{ iTunes track unit sales (thousands) } & & \multicolumn{3}{c}{ iTunes album unit sales (thousands) } \\
\cline { 2 - 3 } \cline { 7 - 8 } Country & Mean & Median & Std. Dev. & & Mean & Median & Std. Dev. \\
Belgium & 133.4 & 130.1 & 21.3 & & 9.8 & 9.7 & 2.2 \\
Germany & 728.1 & 691.6 & 148.9 & & 87.4 & 85.0 & 22.9 \\
Spain & 65.7 & 64.1 & 11.6 & & 10.1 & 9.8 & 2.3 \\
France & 447.7 & 473.9 & 96.6 & & 49.7 & 53.4 & 14.7 \\
Italy & 183.9 & 187.7 & 37.1 & & 18.7 & 18.6 & 4.6 \\
UK & 2899.3 & 2801.9 & 594.0 & & 270.7 & 275.2 & 82.7 \\
Total & 743.0 & 252.6 & 1022.3 & & 74.4 & 25.9 & 98.6 \\
\hline \hline
\end{tabular}

The UK is clearly the largest country in terms of iTunes sales, and Belgium is the smallest. We note from Table 1 that while there is great variance across countries in terms of sales levels, the variance within countries (across weeks) is relatively smaller and less skewed. In spite of the variance in sales across countries, we will show that the average time trend of our control group — on a logarithmic scale closely maps the time trend of France.

Finally, we postulate that because citizens may be confused over when the law actually became effective, we are more likely to see an effect begin when people first became aware of the law rather than when it finally became effective in October 2009. To measure awareness, we collected Google Trends data on

\footnotetext{
${ }^{12}$ For example, we dropped the Country genre not because its market share was too low, but rather because we could find no research or data giving us information as to its a priori tendency to be pirated.
} 
Google searches (from France) for the search term "HADOPI." ${ }^{13}$ Google Trends reports the "relative search index" for a search term in a given country, meaning that for each week we observe the number of searches for that term relative to the average number of all searches in that country across each week in the date range. So, for example, if there were an average of 20,000 searches per week in our date range for the term HADOPI, then in a week where there were 100,000 searches, the Google Trends index would report "5.0" for that week. Thus, while we do not know the actual volume of searches, we know when awareness of HADOPI peaked as measured by Google searches, and the relative height of that peak. This can serve as a measure of national awareness of the law.

\section{Results}

Our basic strategy for determining the impact of HADOPI is to use a difference-in-difference approach, comparing the change in French sales before and after HADOPI to the average change in sales across the control group. However, we have two initial challenges to overcome. First, we need to give evidence that our control group truly can simulate the counterfactual of what France's sales would look like in the absence of HADOPI. Second, we need to determine when we believe is the "treatment date" upon which HADOPI began.

We begin addressing both of these issues with the following model:

$$
\ln \text { Sales }_{i t}=\beta_{0}+\beta_{1} \Omega_{t}+\beta_{2} \Omega_{t} * \text { France }_{i}+\mu_{i}+e_{i t}
$$

Where $\ln \left(\right.$ sales $\left._{i t}\right)$ is equal to the natural log of song sales units in country i during week $t, \Omega_{t}$ is a vector of dummy variables for each week of the data (time fixed effects), France ${ }_{i}$ is an indicator variable equal to 1 for French observations, $\mu_{i}$ is a vector of country fixed effects, and $e_{i t}$ is the idiosyncratic shock term.

\footnotetext{
${ }^{13}$ Google Trends data for other related search terms such as "French Three Strikes Law" show the same pattern.
} 
With this specification, $\beta_{1}$ tracks the average time trend for log sales units over time for the control group, while $\beta_{2}$ estimates how the French time trend differs from this average.

We estimate this model and then plot the results visually in Figure 1 , with $\beta_{0}+\beta_{1}$ representing the average sales time trend for the control countries and $\beta_{0}+\beta_{1}+\beta_{2}$ representing the French sales time trend. Both of these time trends are plotted and measured on the left axis in Figure 1. We also added to this graph the Google Trends relative index for the search term HADOPI (in France), measured on the right axis.

\section{Figure 1: iTunes Single Track Unit Sales Trends (4 majors combined), France vs. Control}

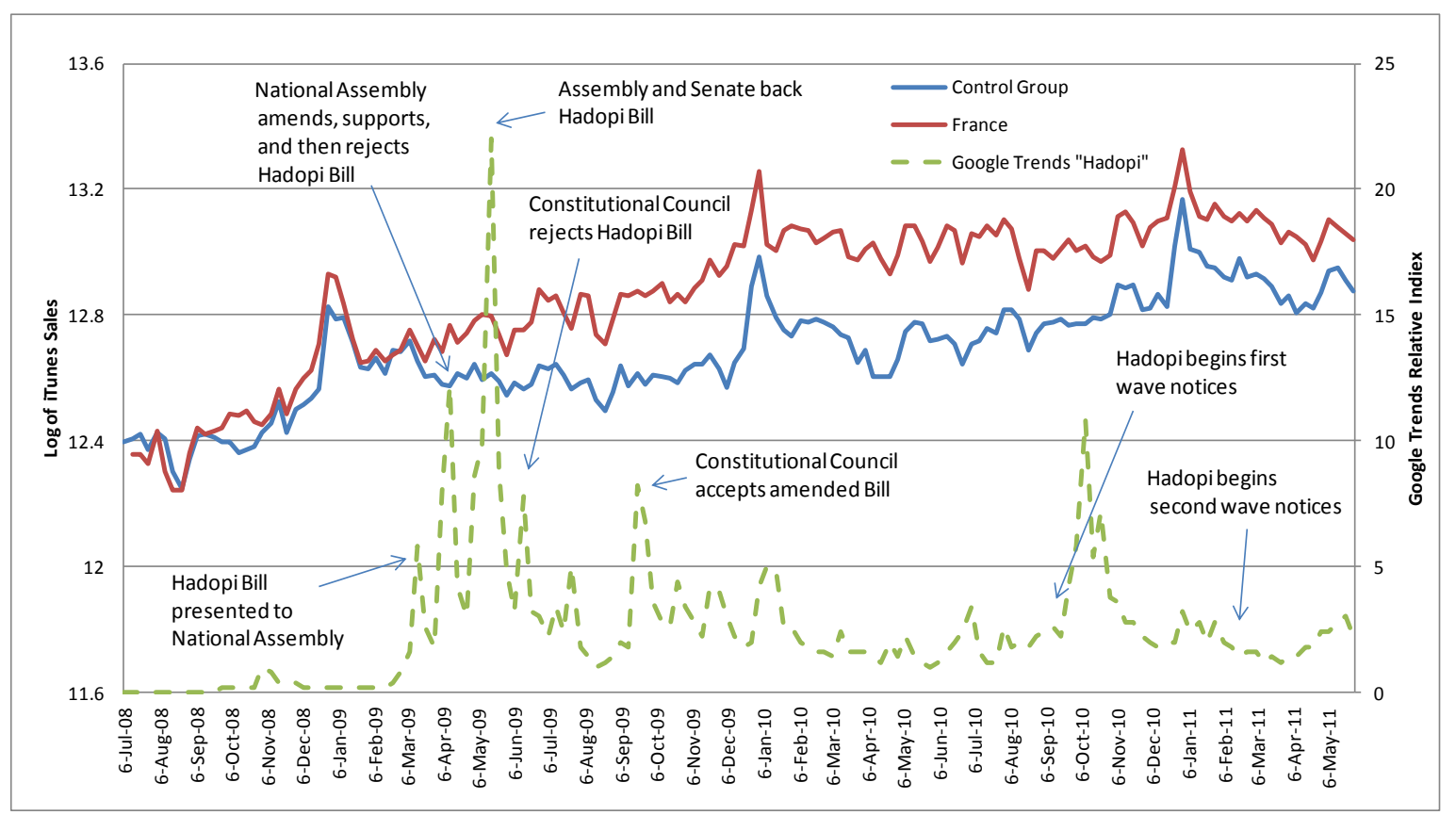

Examining this table, we first note that the initial peak for the Google Trends Index occurs in March 2009, corresponding to the presentation of the HADOPI law to the National Assembly. Prior to March 2009, the French sales trend appears to follow closely the sales trend of the control group. A Wald test of joint significance for all $\beta_{2}$ between July 6, 2008 and March 30, 2009 could not reject the null hypothesis 
that the coefficients are jointly zero at the $95 \%$ confidence level. ${ }^{14}$ Thus, prior to the first Google Trends spike, the time trend for French sales is statistically indistinguishable from the sales trend of the control group. This lends credibility to the identifying assumption of our difference-in-difference model, namely that the control group simulates the counterfactual of how France's sales would have trended in the absence of HADOPI.

Figure 1 also helps to shed light on the question of when to consider the effective treatment date of HADOPI. The final HADOPI law that was passed was not accepted by the Constitutional Council until October 2009, and thus before this date the law was not actually in effect. However, we see the French sales trend diverge from the control group starting in March 2009, and then rise further throughout the following several months. During this time, we also observe two more peaks of HADOPI awareness; the first occurs in April when the National Assembly supports and then rejects the law, and the second is in May when the Assembly and the Senate both backed the law. Because each of these peaks is higher than the last, it seems safe to assume that this reflects growing national awareness of the HADOPI law. Thus, this graph leads us to believe that the effect of HADOPI began with rising awareness of the law and not upon its actual implementation. This seems plausible for the reasons we outlined above. However, in our subsequent analysis we will consider three potential treatment dates: the beginning of media attention and national awareness (March 2009), the month the law went into effect (October 2009), and when HADOPI began to send out notices (September 2010).

We also note a very similar trend for iTunes album sales. We applied the same model as above to iTunes album unit sales and graph the results in Figure 2.

If we accept the identifying assumption that France would have followed the sales trend of the control group if not for HADOPI, then the average effect of HADOPI can be measured as the average gap

\footnotetext{
${ }^{14}$ We clustered standard errors at the country level, as observations of sales levels within a country from week to week are likely to be correlated.
} 
between the two sales trend lines after March 30, $2009^{15}$ (or, whichever date we are testing as a potential treatment date). In order to measure this gap and test for statistical significance, we estimate the following slightly different version of the first model:

$$
\ln \text { Sales }_{i t}=\beta_{0}+\beta_{1} \phi_{t}+\beta_{2} \phi_{t}^{*} \text { France }_{i}+\mu_{i}+e_{i t}
$$

Figure 2: iTunes Album Unit Sales Trends (4 majors combined), France vs. Control

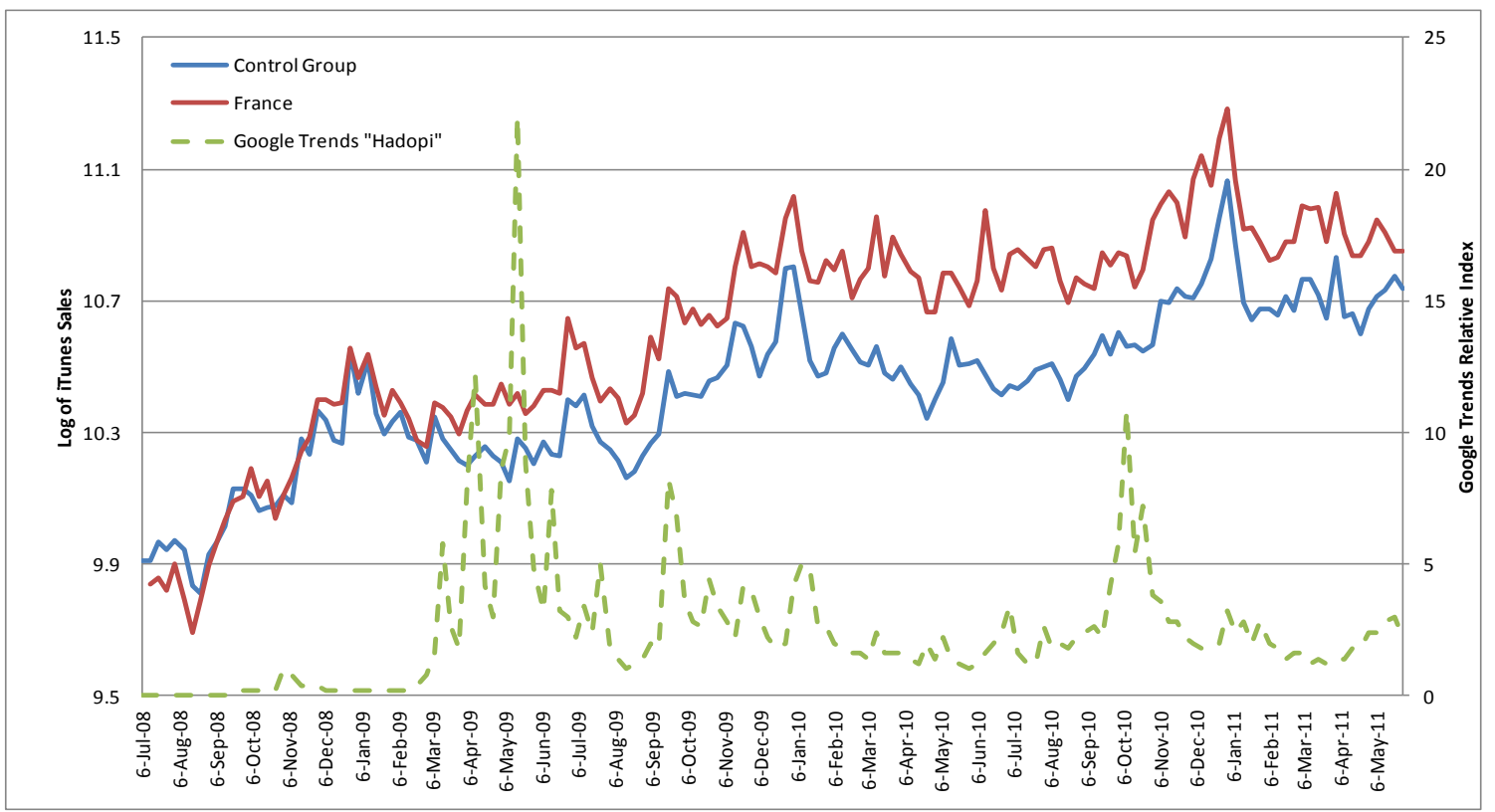

The only difference between (ii) and (i) is that in (ii), $\phi_{t}$ is an indicator variable equal to one if the observation occurs after March 30, 2009 (or October 31, 2009 and September 30, 2010 in our sensitivity tests below). Thus, this model measures the average post-HADOPI change in sales across the control countries $\left(\beta_{1}\right)$ and then estimates any change in French sales over and above the change in the control group $\left(\beta_{2}\right)$. This means that $\beta_{2}$ is the coefficient of interest and under our identifying assumptions, it represents the average causal effect of HADOPI on weekly iTunes sales units in France from March 2009 until May 2011.

\footnotetext{
${ }^{15}$ We note that the use of March 30, 2009 as the treatment date will likely yield a slightly conservative estimate of the impact of HADOPI. In Figure 1, it appears as if French sales may have begun to diverge from the control group during March and that the awareness of the law began to spike in early March, and so our conservative use of March 30 as the start date of HADOPI will bias our difference-in-difference estimate slightly toward zero.
} 
In columns (i) and (ii) of Table 2 we display the results of estimating this model for both single tracks and for albums. Accounting for the fact that our independent variable is in log terms, these estimates indicate that French track sales units rose about $25.5 \%$ in the control group after March 1, 2009 but by $48 \%$ in France, indicating that French iTunes track sales were $22.5 \%$ higher on average than they would have been in the absence of HADOPI. ${ }^{16}$ Similarly, album sales units rose by $42 \%$ in the control group but $67 \%$ in France, indicating that HADOPI increased iTunes album sales an average 25\% per week in France. Standard errors are clustered at the country level, and these difference-in-difference results are statistically significant at the $95 \%$ confidence level. ${ }^{17}$

Table 2: Estimate Effects of HADOPI for Tracks, Albums, and Across Genres

\begin{tabular}{|c|c|c|c|c|c|}
\hline & (i) & (ii) & (iii) & (iv) & (v) \\
\hline & All Tracks & All Albums & $\begin{array}{r}\text { Classical / Folk / } \\
\text { Modern Christian / } \\
\text { Jazz }\end{array}$ & Rock / Pop & Rap / Hip Hop \\
\hline After Hadopi & $\begin{array}{l}0.228 * \\
(0.037)\end{array}$ & $\begin{array}{l}0.351 *^{\top} \\
(0.033)\end{array}$ & $\begin{array}{r}-0.042 \\
(0.072)\end{array}$ & $\begin{array}{r}0.142 \\
(0.068)\end{array}$ & $\begin{array}{l}0.846 * \\
(0.205)\end{array}$ \\
\hline After Hadopi * France & $\begin{array}{l}0.203^{*} \\
(0.037)\end{array}$ & $\begin{array}{l}0.223^{*} \\
(0.033)\end{array}$ & $\begin{array}{r}0.068 \\
(0.072)\end{array}$ & $\begin{array}{c}0.158 * * \\
(0.068)\end{array}$ & $\begin{array}{r}0.260 \\
(0.205)\end{array}$ \\
\hline Constant & $\begin{array}{l}12.520^{*} \\
(0.023)\end{array}$ & $\begin{array}{l}10.168 * \\
(0.020)\end{array}$ & $\begin{array}{l}7.715^{*} \\
(0.044)\end{array}$ & $\begin{array}{l}11.411^{*} \\
(0.042)\end{array}$ & $\begin{array}{l}8.731^{*} \\
(0.127)\end{array}$ \\
\hline $\begin{array}{l}\text { Observations } \\
\text { \# of Countries } \\
\text { R-squared } \\
\end{array}$ & $\begin{array}{r}918 \\
6 \\
0.361 \\
\end{array}$ & $\begin{array}{r}918 \\
6 \\
0.417 \\
\end{array}$ & $\begin{array}{r}912 \\
6 \\
0.082^{\prime} \\
\end{array}$ & $\begin{array}{r}912 \\
6 \\
0.103 \\
\end{array}$ & $\begin{array}{r}912 \\
6 \\
0.42 \\
\end{array}$ \\
\hline $\begin{array}{l}\text { Robust standard errors } \\
+ \text { significant at } 10 \% \text {; } \\
\text { March } 30,2009 \text { is count } \\
\text { Columns (i) and (ii) inc }\end{array}$ & $\begin{array}{l}\text { eses } \\
\text { at } 5 \% \text {; }{ }^{*} \text { sign } \\
\text { eginning of } \\
\text { om all four }\end{array}$ & pi $1 \%$ & nns (iii) through (v) re & data from onl & two. \\
\hline \multicolumn{6}{|c|}{$\begin{array}{l}\text { Additionally, we estimated this model for the } 6 \text { months before and after the month the law became effective } \\
\text { (October 2009) since fully informed, rational consumers need not change their behavior until then. The coefficient } \\
\text { of interest is smaller in this specification and significant only at a } 90 \% \text { confidence level. We also estimated the } \\
\text { model for the } 6 \text { months before and after September } 2010 \text {, as this was the first month that HADOPI began sending } \\
\text { out first notices. In this case, the resulting coefficient was close to zero and statistically insignificant. We suggest } \\
\text { that consumers likely reacted more to the media attention in March-May } 2009 \text { both due to its salience and because it } \\
\text { may have been unclear to them when the law actually became effective. } \\
17 \text { There has been some recent criticism of standard methods for clustering standard errors in difference-in-difference } \\
\text { models when the number of groups is small. See, for example, Bertrand (2003). We also collapsed the data into } 12 \\
\text { observations, summing up track sales for each country before and after March } 30 \text {. When we estimate the model on } \\
\text { these } 12 \text { observations, the coefficient of interest (the France-after interaction) is still estimated as } 0.2 \text { and is still } \\
\text { significant at the } 95 \% \text { confidence level. }\end{array}$} \\
\hline
\end{tabular}


In addition to these aggregate results, we also estimated the same models for each of the four major labels individually, and the results for each individual label exhibit roughly the same patterns as the aggregated results (particularly in sign and significance). Thus, it is unlikely that our results are driven by the marketing efforts or release schedule of an individual firm. As well, marketing, advertising, and release schedule decisions must — by law — be made non-cooperatively, making it less likely that they will be correlated across labels. In short, the effects we have observed thus far appear to be industry-wide and not specific to any particular label's music.

As one additional falsification check, we chose one country at random from our control group (Spain) and ran the same difference-in-difference model as above, using March 30, 2009 at the treatment date, but with Spain as the treatment country and the other four countries (France was not included) as the control group. Because there was no major policy change in Spain as this time, we would expect to see no significant shift in sales in Spain relative to the control group. Indeed, the coefficient of interest was small and statistically insignificant when estimating the model in this manner.

\section{Genre Analysis}

Policy changes such as these are often difficult to study due to a lack of experimental power. Indeed, although we observe five control countries over time, we only observe one experiment: the passage of HADOPI in France. One could argue that some other French-specific factor may have coincidentally affected France's music sales levels at exactly the same time as public awareness of HADOPI. While we believe that it is unlikely that the timing of this would coincide with the passing and awareness of HADOPI, it is difficult to rule out this possibility based on the preceding tests.

To attempt to address this concern we use another approach, by adding an additional level of difference to the model based on priors about the popularity of piracy across various genres of music. Specifically, EMI surveys of French citizens show that that Rap and Hip Hop are the most heavily pirated genres, even relative to popularity in legal sales channels. While Rock and Pop experience average levels 
of piracy, the data also indicate that genres such as Classical, Christian, Folk, and Jazz experience significantly lower levels of piracy. ${ }^{18}$ Note that other published studies suggest a similar distribution of pirated downloads across genres. ${ }^{19}$ This allows us to increase the number of experiments in that we can treat each genre as a unique experiment based on its a priori tendency to be pirated. If the observed increase in French sales is due to a reduction in piracy triggered by HADOPI, then we would expect the increase in Rap sales to be larger than that for Rock and Pop and the increase for Classical, Christian, etc. to be quite low.

In columns (iii), (iv), and (v) of Figure 2 we see that that the rise in French sales after HADOPI (relative to the control) is indeed highest for the most heavily pirated genres (column v) and is small and statistically insignificant for the least pirated genres (column iii). We conducted an F-test across each estimation to test whether the estimate of the effect of HADOPI on French sales is different across genres. Due to relatively large standard errors (especially for Rap and Hip Hop), we cannot reject the null hypothesis the post HADOPI French increase in rap/hip hop is the same as for other genres. However, we can reject with $90 \%$ confidence the null that the French increase (above the control group) in Rock/Pop is the same as for less pirated genres like Classical and Jazz. Nonetheless, the point estimates indicate that that while the effect of HADOPI on Classical, Christian, Folk, and Jazz was to increase French sales by 7\%, the point estimate of the effect on Rock and Pop was $17 \%$ and the effect on Rap and Hip Hop was a $30 \%$ increase.

Unobserved changes that might increase French music sales (coincidentally around the same time as HADOPI) would be unlikely to have this same pattern across genres. For example, if Apple began to heavily promote the iTunes store in France more so than in the control countries around the same time as HADOPI, one would expect such promotions to affect each genre equally, at least proportionally to prior

\footnotetext{
${ }^{18}$ These genre findings are based on surveys performed by EMI Music in France in France during October and November 2010. 8,173 interviews were completed and results were weighted to nationally representative figures. The data are not publicly available but were available to the authors.

${ }^{19}$ For example, Liebowitz (2008).
} 
sales. Instead, we see sales in France for heavily pirated genres rise faster than for less pirated genres, which suggests that this sales increase is due to a reduction in French piracy levels. This is consistent with the idea that the difference-in-difference increase we observe in France is actually attributable to HADOPI.

\section{Discussion}

Combined, the four major labels sold an average of 491,000 tracks per week in France after March 2009. Our findings indicate that in the absence of HADOPI, if France followed the same trend as the control group, ${ }^{20}$ sales would have averaged only 401,000 units per week. Thus, our results suggest that the HADOPI law (and the education and media attention surrounding it) increased iTunes single sales by 90,000 units per week on average. If we assume an average song price of $€ 1$ per song, this equates to an increase of $€ 4.7$ million ( $\$ 6.3$ million) in annual iTunes track revenues.

Likewise, average iTunes album sales were about 56,000 units per week in France after March 2009. In the absence of HADOPI, we estimate that iTunes album sales would have averaged only 44,800 albums per week. Thus, our results suggest that HADOPI causally increased French digital albums sales by an average of 11,200 units per week. Assuming an average of $€ 8.5$ per album, this equates to an increase of $€ 4.9$ million (\$6.7 million) in annual iTunes album sales due to HADOPI. Together, we estimate that HADOPI increased annual iTunes revenues (tracks plus albums) by about $€ 9.6$ million ( $\$ 13$ million) per year for the four majors combined. ${ }^{21}$ Under the assumption that the four majors make up $70 \%$ of the industry, if sales for the remaining $30 \%$ of artists experienced the same change in sales as we observe for the major labels then the impact of HADOPI was to increase overall digital iTunes sales by $€ 13.8$ million (\$18.6 million) per year for the entire music industry. We note that this number addresses only the effect

\footnotetext{
${ }^{20}$ Which they did for the period of time from July 2008 until March 2009.

${ }^{21}$ According to sources inside the major labels, about $30 \%$ of this goes to iTunes while the other $70 \%$ is split in some manner between the label and the artist.
} 
of HADOPI on sales of one form of media (music) in one channel (iTunes), and thus is likely a lower bound on the true impact of HADOPI on the media industries.

We also note that the effect of HADOPI was larger for more heavily pirated genres like Rap and smaller for less pirated genres like Christian music or Jazz, suggesting that the increase in sales is likely caused by a reduction in piracy. It is worth noting we observed this sales pattern for each of the four majors when analyzed separately, providing some support our assumption that HADOPI may have had the same effect on the independent labels (the other $30 \%$ of the market).

The most interesting, and potentially surprising, part of this conclusion is that the study occurs before anyone received a third notice (i.e. before any cases have been referred to the criminal court), and that the increase in sales is observed even before the law's final passage. While this may seem irrational, it is consistent with the idea that increasing the salience of the law, the illegality of piracy, and the potential penalties is sufficient to change user behavior. In this regard, we note the significant discussion in the media about the illegality of piracy while the law was being debated, and that after the passing of the law, the HADOPI agency has also conducted extensive awareness and education campaigns about the illegality of media piracy and the legal alternatives that are available. Thus, we cannot determine whether the continued effectiveness of HADOPI is due entirely to the threat of sanctions or due to the combination of the sanctions, the media buzz, and the educational/awareness campaigns. Disentangling the effects of the positive reinforcement actions like education from the negative reinforcement actions like sanctions is a fruitful area for future research.

A finding that education and salience have a strong impact on user behavior is consistent with those of Bhattacharjee et al. (2008), who find that public awareness of a very small number of major lawsuits conducted by the RIAA against music file-sharers reduced national supply and demand for pirated content on P2P networks. However, unlike Bhattacharjee we do not find that the effect is short-lived. We suggest that with regard to mitigation of sales displacement by piracy, a national anti-piracy policy 
combined with educational efforts is much more effective in the longer term than a small number of highprofile lawsuits.

As noted above, a limitation of our study is that we only observe data for one industry (music), in one channel (iTunes). As such, our study likely understates the true sales impact of HADOPI. Within the music industry, physical CD sales are still a large component of music industry revenues; and while data limitations prevented us from considering the effect of HADOPI on CD sales, there sales may have also have benefitted from HADOPI (other academic studies have shown that filesharing displaces physical CD sales).

HADOPI may have also benefitted other channels for distributing music. For example, during this time legal music streaming services have become popular in Europe. These services provide revenues to the music industry in several manners not measured by this study. It is quite likely that illegal downloaders who choose to quit pirating due to HADOPI might turn to legal streaming services (such as Deezer, MusicMe or YouTube), meaning that revenue from streaming and other digital music sales channels may have increased due to HADOPI as well. However, some of these services — such as Deezer — were adopted after the impact of HADOPI, leaving us with no pre-HADOPI period to study. As well, growth trends in these services seem to vary greatly across countries, making selection of a control group difficult at best.

In short, while we suspect that revenues from these or other similar services have benefitted from HADOPI, we are unable to evaluate this claim with the same rigor or precision that we could with iTunes sales. As such, we believe that the $€ 13.8$ (\$18.6) million per year increase in French iTunes revenues suggested in our results should be taken as a lower bound on the total effect that HADOPI has had on music industry revenues.

Additionally, other industries may benefit from HADOPI as well. For example, to the degree that the motion picture and publishing industries suffer losses caused by filesharing, HADOPI may positively 
impact revenues in those industries. So our study does not quantify the entire effect of HADOPI on producer surplus in the media industries, but merely indicates that for one industry (music) in one channel (iTunes), the law has had a large and statistically significant effect. Our estimate alone cannot be weighed against the costs of HADOPI, but may serve as an early indication that HADOPI and laws like it can mitigate the displacement of media sales by piracy. In order to fully capture the benefits of HADOPI, researchers would need to measure its effects on all forms of media in all sales channels and also observe whether the magnitude of the effect changes as third notices go out and sanctions begin to be imposed. And these benefits would also have to be linked to any potential increases in the supply or quality of music produced.

For policy-makers, our results may have important implications in other countries that are considering the passing of similar graduated response laws, as well as in France where a number of parties still oppose the continued existence of the law. Likewise, our results may inform industry practice in some countries, like the US, that have seen the voluntary agreement on application of a graduated response system between the music industry and the ISP's without requiring direct government intervention. In the context of ongoing policy debates, we also wish to point out that our results should be viewed only in the context of efforts to influence the demand-side of piracy (i.e., through educating and influencing consumer behavior). It is unclear whether efforts to influence the supply-side of piracy (such as site blocking proposed in the Stop Online Piracy Act currently under debate in the United States) will be similarly effective in changing consumer behavior. Indeed, this could be a useful area for future research.

Finally, we wish to point out that our results only address the impact of this legislation on industry revenue. Our study does not address the costs of this or other anti-piracy interventions. These costs could accrue either through the direct costs of implementing and enforcing the legislation, or through indirect social costs and potential side-effects associated with implementing such anti-piracy legislation, and such costs should be balanced against potential benefits in any discussion of policy change. 


\section{References:}

Bertrand, M., E. Duflo, and S. Mullainathan (2003) "How Much Should We Trust Dixerences in Differences Estimates," NBER Working Paper 8841.

Bhattacharjee, S., R. Gopal, K. Lertwachara, and J. Marsden (2006). "Impact of Legal Threats on Online Music Sharing Activity: An Analysis of Music Industry Legal Actions.' Journal of Law and Economics. Vol. 49, pp 91-114.

Christin, N., A. Weigend, J. Chuang. 2005. Content Availability, Pollution, and Poisoning in File Sharing Peer-to-Peer Networks. Proceedings of the 6th ACM conference on Electronic commerce, pp. 68-77.

Danaher B., Dhanasobhon S., Smith M.D., and Telang R. (2010) "Converting Pirates Without Cannibalizing Purchasers: The Impact of Digital Distribution on Physical Sales and Internet Piracy" Marketing Science, Volume 29 Number 6. pp. 1138-1151.

Danaher, B., J. Waldfogel (2011). "Reel Piracy: The Effect of Online Movie Piracy on Film Box Office Sales.” Working Paper. Wellesley College. Boston, Massachussetts.

Deleersnyder, B., I. Geyskens, K. Gielens, M.G. Dekimpe (2002). "How Cannibalistic is the Internet Channel? A study of the newspaper industry in the United Kingdom and The Netherlands." International Journal of Research in Marketing 19(4) 337-348.

Desai, Preyas, Debu Purohit, and Dinah Venik (2009), "Downloadable Music Set Free: The Flip Side of DRM Protection.” Working Paper, Fuqua School of Business, Duke University.

$\mathrm{Hu}, \mathrm{Yu}$ and Smith, MD (2011). "The Impact of Ebook Distribution on Print Sales: Analysis of a Natural Experiment." Working Paper. Available at http://papers.ssrn.com/sol3/papers.cfm?abstract_id=1966115.

Hui, Kai-Lung and Png, Ivan (2003) "Piracy and the Legitimate Demand for Recorded Music," Contributions to Economic Analysis \& Policy: Vol. 2: Iss. 1, Article 11.

IFPI (2010). IFPI Response to Commission Green Paper on Creative and Cultural Industries. July 2010.

Kemerer C., Liu C., and Smith MD (2011), "Strategies for Tomorrow's "Winners-take-some" Digital Goods Markets." Working Paper. Available at http://www.pitt.edu/ ckemerer/Kemerer-Liu-Smith-Submitted.pdf.

Liebowitz, Stan (2008). "File-Sharing: Creative Destruction or just Plain Destruction?" Journal of Law and Economics, Vol. 49 p1-28.

Liebowtiz, Stan (2008) “Testing File-Sharing's Impact by Examining Record Sales in Cities.” Management Science, Vol. 54 No. 4, pp 852-859.

Liebowitz, Stan (2011). "The Metric is the Message: How much of the Decline in Sound Recording Sales is due to File-Sharing?," Working Paper, University of Texas at Dallas.

Oberholzer, F., K. Strumpf. 2007. The Effect of File Sharing on Record Sales. An Empirical Analysis. Journal of Political Economy, 115(1) 1-42. 
Oberholzer-Gee, Felix and Strumpf, Koleman. "Filesharing and Copyright." (2009) NBER's Innovation Policy and the Economy series, volume 10. MIT Press.

OECD (2009). Magnitude of Counterfeiting and Piracy of Tangible Products. November 2009.

Peitz, M, and P. Waelbroeck (2004). The Effect of Internet Piracy on Music Sales: Cross-Section Evidence. Review of Economic Research on Copyright Issues, 1(2) 71-79.

Rob, Rafael and Waldfogel, Joel, (2004). "Piracy on the High C's: Music Downloading, Sales Displacement, and Social Welfare in a Sample of College Students." Journal of Law and Economics, 49(1) 29-62.

Rob, Rafael and Waldfogel, Joel, (2007). Piracy on the Silver Screen. Journal of Industrial Economics, 55(3) 379-393.

Sinha R.K., Machado F.S., and Sellman C. (2010). "Don't Think Twice, It's All Right: Music Piracy and Pricing in a DRM-Free Environment.” Journal of Marketing: Vol. 74, No. 2, pp. 40-54.

Waldfogel, J. (2009). "Lost on the web: Does web distribution stimulate or depress television viewing?" Information Economics and Policy, 21(2), 158-168.

Waldfogel, Joel (2011). "Bye, Bye, Miss American Pie? The Supply of New Recorded Music Since Napster.” NBER Working Paper No. 16882.

Zentner, Alejandro, (2006). "Measuring the Effect of File Sharing on Music Purchases" The Journal of Law and Economics, volume 49 pages 63-90

Zentner, Alejandro, (2005). "File Sharing and International Sales of Copyrighted Music: An Empirical Analysis with a Panel of Countries," Topics in Economic Analysis \& Policy: Vol. 5 : Iss. 1, Article 21. 